\title{
Organizational Change Skills: An Empirical Cross-National Study
}

\author{
Karen Somerville $^{1^{*}}$, Inta Cinite ${ }^{2}$, Carlos Largacha-Martínez ${ }^{3}$ \\ ${ }^{1}$ Athabasca University, Athabasca, Alberta, Canada \\ ${ }^{2}$ Ghubril Ltd., Toronto, Canada \\ ${ }^{3}$ Fundación Universitaria del Area Andina, Bogota, Colombia \\ Email: ^karen@performanceplusgroup.com
}

How to cite this paper: Somerville, K., Cinite, I., \& Largacha-Martínez, C. (2021). Organizational Change Skills: An Empirical Cross-National Study. Open Journal of Business and Management, 9, 894-911.

https://doi.org/10.4236/ojbm.2021.92048

Received: January 15, 2021

Accepted: March 28, 2021

Published: March 31, 2021

Copyright $\odot 2021$ by author(s) and Scientific Research Publishing Inc. This work is licensed under the Creative Commons Attribution International License (CC BY 4.0).

http://creativecommons.org/licenses/by/4.0/

\begin{abstract}
This research is premised on the proposition that mastering organizational change skills may help improve success rate of change initiatives. The overall purpose of this empirical, cross-national study was to explore whether perceptions of organizational change skills differ across nations. Using a convenience sample, structured interviews were conducted with 90 managers and executives in three regions: the USA, the Baltics and South America to collect quantitative and qualitative data. Statistical significance of between-group differences in means was obtained with the help of one-way ANOVA, and differences in percentages were established using a chi square test. Most of the change skills were perceived similarly across the three regions, but nevertheless, there were some differences. More communication and managing the change process skills were believed to be present in organizations in the USA, while understanding internal and external environment was more characteristic of the Baltics and South America. Respondents in these two regions also considered interpersonal and social skills to be more important. Respondents' awareness of change skills was quite low without prompting. However, when prompted, all pre-established 11 groups of skills (Somerville \& Whelan-Berry, 2009) were rated as important, and the majority of respondents were confident that these skills could be found in their organization. Given the relatively few differences that were found across the three regions, this suggests that cross-border dissemination of organizational change skills is possible, but each geography requires a slight adaptation. The findings also suggest that if those leading/managing change initiatives recognize that there are at least 11 groups of change skills, and cultivate these skills within the organization, this could increase the success rate of change initiatives. Given the paucity of empirical research relating to change skills generally, and cross-national considerations specifically, and the importance of change for organizations globally, this exploratory empirical research makes important contributions.
\end{abstract}




\section{Keywords}

Organizational Change, Change Skills, Empirical Research, Cross-National

\section{Introduction}

Organizational change is an inherent part of daily life in today's organizations (e.g., Grady \& Grady III, 2013; Van der Smissen, Schalk, \& Freese, 2013; Burke, 2018; Burk, 2019). Indeed, for organizations to sustain their existence and success, change is the norm (Al-Haddad \& Kotnour, 2015). Kotter (2012) suggested that perhaps the biggest challenge facing business leaders is how to stay competitive in the face of constant turbulence and disruption.

It is widely accepted among scholars that organizational change is an extremely difficult endeavour (e.g., Jansson, 2013) which makes it risky (Jacobs, Van Witteloostuijn, \& Christe-Zeyse, 2013). Further, organizations are operating in an increasingly complex global environment (Burk, 2019). Numerous researchers continue to report that the failure rate for organizational change efforts is over 70\% (e.g., Brakman, Garretsen, Van Marrekijk, \& Van Witteloostuijn, 2013; Anand \& Barsoux, 2017; Onderick-Harvey, 2018) and not getting any better (Al-Haddad \& Kotnour, 2015). As noted by Kotter (2008), “A 70 percent failure rate is an enormous drag on a company, a government, an economy or a society. Investors are obviously hurt, but the pain goes in all directions: to employees, customers, our families" (p. 13). Various reasons have been cited for the significant levels of failure of organizational change initiatives, including a lack of knowledge about planning and implementing organizational change (Burke, 2018). Our empirical research takes this further than just knowledge-we focus on change skills that may help improve the success rate of organizational change initiatives. As noted by Spencer and Spencer (1993), skill is developed by applying knowledge. While there has been an "avalanche" of research and managerial attention to change management practices (Buono, Adams, \& Schwarz, 2019), relatively little attention has been dedicated to organizational change skills.

Much of the change management literature reports studies conducted predominantly in the western world, and it is not certain to what extent their findings apply to other regions. Although there are grounds to believe some practices may transcend borders (Jansson, 2013; Schaffer, 2010), there is also a school of thought that maintains that the way organizational change is implemented and managed is unique to each culture (e.g. Jacobs et al., 2013). Consequently, it can be questioned whether skills required to manage change also vary with each culture. The main purpose of this empirical, cross-national study was to explore whether organizational change skills differed across nations. We selected three geographically dispersed parts of the world: the USA, the Baltics and South America.

The paper is structured as follows: first, the theoretical framework introduces 
organizational change skills, which are at the core of this research, and cross-national context in which these skills are studied; second, the methods section covers the study design and the analytical framework; third, the results are presented to answer the posed research questions; and the paper ends with a discussion and conclusions.

\section{Organizational Change Skills}

The theoretical underpinning of this research is based on the seminal work of Nadler and Tushman (1990), which hypothesized that organizational change requires "skills in building executive teams, roles, and systems in support of the change, as well as institutional skills in diffusing leadership throughout the organization" (p. 81). Change management skills have been identified as key skills for decades (e.g., Beer \& Nohria, 2000; McCauley, 2006; Levasseur, 2013; Stouten, Rousseau, \& De Cremer, 2018). Warrick (2006) hypothesized that next to leadership skills, organization development and change skills are the most important skills leaders and employees need to develop in these times of dynamic change. Burke (2011) noted that "the need for expertise in organizational change has never been greater" (143), and numerous researchers (e.g., Momcilovic, Nikolic, \& Arsovski, 2016; Anand \& Barsoux, 2017) have highlighted the need for developing leaders. But, surprisingly, a review of the literature sheds relatively little information about what specific change skills are required within organizations (Nikolaou, Gouras, Vakola, \& Bourantas, 2007; Somerville \& Turner, 2013). We agree with Buono and Subbiah (2014) that developing change capacity within the organization is vital to survival and long-term organizational success. But in order to develop that capacity, there must be clarity regarding the specific organizational change skills that are required for successful organizational change.

The summary of the organizational change skill literature developed by Somerville and Whelan-Berry (2009) continues to be the most comprehensive based on our review of the literature. The authors had identified 11 groups of organizational change skills. Table 1 provides the list, along with a brief explanation. These 11 groups of organizational change skills were later validated by Somerville and Turner (2013) in their empirical research.

\section{Cross-National Research}

One dominating assumption relating to organizational change is "that organizational change practices are universal in nature" (Jansson, 2013; Schaffer, 2010). However, as noted by Jacobs et al. (2013) "scholars of organizational change cannot continue to assume with a quiet heart, that the change patterns in their corner of the world reflect those experienced on a wider, global stage" (779). Similarly, it can be assumed that skills necessary to implement change practices may also vary across nations. Our study, based on interviews with a sample of 90 senior managers and leaders from three selected geographies, was conducted 
from a cross-national perspective to explore whether perceptions about organizational change skills are universal in nature. In particular, we were interested in whether there is a perception that change skills are available in these three regions, and whether the importance of specific change skills is perceived differently across these three regions.

The increased focus on global business in the $21^{\text {st }}$ century has resulted in a growing body of research concerning international management (Tsui, Nifadkar, \& Ou, 2007). Globalization creates both opportunities and challenges (House, Javidan, Hanges, \& Dorfman, 2002). When organizations expand their operations beyond domestic markets, they invariably encounter new business and management practices that may differ from the ones they adhere to at home. There is a growing body of literature that reports the impact of various nations on how business is done, what is valued in organizations, how people are lead, and how employees relate to the organization (Kirsch, Chelliah, \& Parry, 2012; Triandis, 1993). Understanding these cross-cultural differences can be expected to lead to better outcomes in multi-national organizations. Researchers, in turn, by examining the impact of culture on various organizational aspects can broaden the range of variables for study that typically are not considered in management research (Triandis, 1993). On the other hand, there is a stream of thought that some organizational practices are universal in nature (House, Javidan, Hanges, \& Dorfman, 2002).

Table 1. 11 groups of change skills (adapted from Somerville \& Whelan-Berry, 2009).

\begin{tabular}{|c|c|}
\hline Groups of Change Skills & Brief Explanation \\
\hline Managing the Change Process & $\begin{array}{l}\text { Skills in this group focus on the steps of the change process, including knowing what needs to be changed, } \\
\text { convincing people of the need for change, developing comprehensive plans, and implementing policies and } \\
\text { procedures to embed the changes within the organization. }\end{array}$ \\
\hline Resistance and Conflict & $\begin{array}{l}\text { This relates to managing the change process and focuses on effectively managing the resistance and conflict } \\
\text { relating to the changes. }\end{array}$ \\
\hline Coalitions and Networks & $\begin{array}{l}\text { This also relates to managing the change process and includes skills to build and manage effective coalitions } \\
\text { and networks both internally and externally relating to the change initiative. }\end{array}$ \\
\hline Vision & $\begin{array}{l}\text { This also relates to managing the change process that including developing a desirable, realistic vision for the } \\
\text { change and translating the vision into workable strategic and tactical plans. }\end{array}$ \\
\hline Resources & $\begin{array}{l}\text { This also relates to managing the change process that includes ensuring adequate resources for the change } \\
\text { initiative and related effective budgeting. }\end{array}$ \\
\hline Communication & $\begin{array}{l}\text { Effective communication skills include the ability to speak, write and listen, in change management } \\
\text { communication about change visions and their ongoing implementation are seen as important. }\end{array}$ \\
\hline Interpersonal and Social & $\begin{array}{l}\text { This includes a broad range of interpersonal and social skills such as inspiring, motivating, influencing, } \\
\text { identifying the concerns of others and treating people fairly. }\end{array}$ \\
\hline Change Leadership & $\begin{array}{l}\text { These skills include self-confidence, emotional resilience in relation to setbacks and difficulties, and making } \\
\text { difficult decisions. }\end{array}$ \\
\hline Power and Politics & These skills include negotiating effectively to gain support, and addressing power and political dynamics. \\
\hline Internal and External Environment & $\begin{array}{l}\text { These are skills to analyze and understand the internal and external environmental factors and dynamics } \\
\text { concerning the change initiative. }\end{array}$ \\
\hline Trust & These skills include the ability to build and maintain trusting relationships. \\
\hline
\end{tabular}


Often cross-national research starts with comparing the USA model and analyzing how other countries may differ from the USA (Tsui et al., 2007). A review of the literature concerning organizational change reveals a massive amount of literature on organizational change in the USA. Many other regions have, however, received less attention in this regard. Nowadays when change has swept organizations well beyond the USA, the lack of substantial insights into cross-national change practices may hinder understanding thereof and slow down dissemination of relevant good practices across borders. This study was designed to contribute to the body of literature that has started closing this gap. We selected South America and the Baltics as locations that are culturally different from the USA, and also experiencing considerable change. In addition, organizational change in these regions has not been studied as extensively as in the USA. The following three sub-sections provide a brief overview concerning change in the USA, the Baltics and South America in recent decades.

\section{The USA}

From the 1950s until the mid-1980s, organizations in the USA were relatively stable (Powell, 2001). However, in the 1980s, mergers and acquisitions became popular, driving significant change for many organizations. The economic downturn in the late 1980s resulted in significant downsizing and restructuring. Downsizing continued into the 1990s, even in profitable companies, for example, AT\&T, a highly profitable company known for its job security, laid off 40,000 employees in 1996 (Powell, 2001).

Starting in the 1990s, globalization and technological change became major forces for many USA organizations (Powell, 2001). In a longitudinal study of 396 firms between 1996 and 2010, O'Hagan-Luff and Berrill (2016) found that the majority of multinational corporations in their study were pursuing at least a semi-global strategy. There also have been two "crisis periods" in the USA since the early 1990s: the dotcom bubble that emerged in 1999/2000 and the credit crisis that hit in 2007/2008 (O'Hagan-Luff \& Berrill, 2016). These forces of mergers and acquisitions, downsizing, restructuring, crises, globalization and technological change have resulted in considerable organizational change in the USA in the past three decades.

\section{The Baltics}

The Baltics (Estonia, Latvia and Lithuania) have experienced considerable political, social and economic changes which, in turn, have significantly impacted their organizations. Separation of the Baltics from the Soviet Union in 1991 brought along a collapse of state-controlled economy, a shift to a western world democracy and free market, transformation of the social fabric, and shift in attitudes and values (e.g., Alas \& Sharifi, 2002; Melnikas, Baršaukas, \& Kvainauskaité, 2006). Furthermore, joining the European Union in 2004 introduced new institutional systems and later also a Eurozone currency (Alas, Kaarelson, \& Rees, 2014). These large-scale environmental changes forced both public and private organizations to change their ways of operating. 
Having lost the Soviet market, Baltic companies had to compete in the European market. To this end, they introduced new business strategies, new management practices, attempted a more democratic and participatory leadership style, launched major structural changes, created new financial instruments, and sought new business opportunities and partners in other countries (Alas et al., 2014; Baumane, 2010; Elenurm, 2007; OECD, 2003). A few studies related to the Baltics have observed that the lack of culture of change, little experience in change management, old mindsets and inertia, and employee opposition to change hinder change initiatives (Alas \& Sharifi, 2002; Baumane, 2010).

\section{South America}

In the late 1980s, South America started experiencing significant change with the opening of the economy, however, it was not ready to be part of globalization (Stiglitz, 2002). Corporations needed to change quickly and new innovation in management platforms was introduced in the 1990s in South American companies, such as total quality management and just in time management. As noted by Soriano (2012) concerning South American organizations, "Alteration in markets that is brought about by economic, political and cultural changes often makes it difficult for business organizations to adapt to new circumstances" (653).

According to Pérez (2009), another challenge for South America is that small companies have not acquired new management practices, and many continue to use old traditional management. Several are family-owned companies established 50 years ago, in which the founder didn't have any type of undergraduate training (Pérez, 2009). Some of these companies, for example, are referred to as having "feudalist management", as in the case of Colombia (Pérez, 2009). Thus, an overall result is learning through doing and interacting. This kind of training limits the ability of companies to produce standard quality products. Most of the knowledge remains tacit (Martínez, Belso-Martínez, \& Más-Verdú, 2012). However, South American companies are now making changes rapidly to become global competitors (Assis-Dorr, Palacios-Marques, \& Merigó, 2012).

\section{Summary-Cross National Research and Research Questions}

As this brief review shows, the three selected regions for this study differ in terms of their history, political events, and economy. While organizational change has captured some attention in cross-national research, the literature on change skills is scarce, and it does not offer any insights in cross-national differences. Nevertheless, there is a reason to hypothesize that geography-specific change practices may call for dissimilar change skills. Our study, therefore, aims to discover how organizational leaders in the USA, South America (Colombia, Argentina, Venezuela and Peru) and the Baltics (Estonia, Latvia and Lithuania) perceive the prevalence and importance of change skills, and whether there is a difference in perceptions across regions. Leaders have a key role in ensuring that necessary change skills are available for change initiatives. Given the lack of empirical research regarding change leadership (By, Hughes, \& Ford, 2016), we see 
this empirical study as an important contribution to the literature.

Given the dominating assumption that change practices are universal in nature (Jansson, 2013; Schaffer, 2010) and Jacobs et al.'s (2013) caution noted earlier in this paper that we cannot continue to assume that change patterns in one part of the world reflect what is going on globally, this cross-national study focused on two research questions concerning organizational change skills in the USA, South America and the Baltics.

1) Is the availability of change skills within organizations perceived differently across the three regions?

2) Is the importance of specific organizational change skills to successfully implement organizational change perceived differently across the three regions?

\section{Method}

\section{Survey Design and Measurement Scales}

We focused on the respondents' perceptions as the objective answers to these questions are typically not available within organizations. Early in the interview, respondents were asked an open-ended question without any prompts regarding their perception of change skills that are available within their organizations and organizational change skills that their organizations had sought from management consultants. The purpose of this question was to identify the degree of awareness of skills necessary for the successful implementation of organizational change.

Next, the interview considered the 11 groups of change skills established through a comprehensive literature review (Somerville \& Whelan-Berry, 2009). Two scales were used for their measurement. Questions asking about presence of change skills within organizations or sought from management consultants used a 3-point scale: "yes, somewhat, no", whereas importance of skills was measured on a 7-point scale with 1 being "unimportant" and 7 being "very important". In addition, the survey included a list of pre-determined four types of organizational change. Frequency of these changes was established by asking respondents whether they have taken place in their organizations (a yes/no question).

The interviews also included several demographic questions: respondents' gender, job level and work experience since graduation. Two questions addressed characteristics of the organizations represented in the sample: their size and industry.

\section{Sample}

We used a convenience sample of 30 respondents from each of the three regions: the USA, South America and the Baltics-90 respondents in total ${ }^{1}$. The identified participants came from a broad range of industries and organizational

${ }^{1}$ Sample size of 30 from each region was selected based on the Central Limit Theorem assumption that at $n=30$ the data start approximating a normal distribution, and their mean and variance resemble those of the population the sample is drawn from (e.g., Greenwood \& Sandomire, 1950; Hogg, Tanis, \& Zimmerman, 2015; Kumar, 2021). Researchers sometimes use $\mathrm{n}=30$ as a rule of thumb. By no means can it be considered an optimal sample size, but rather a minimum sample size that renders statistical tests valid. 
sizes, and were assumed to be knowledgeable of the change processes in their organizations since the majority held managerial positions.

Given the non-probability sampling method, we made sure no more than two respondents came from the same organization. The majority of the South American sample came from Colombia (27) with one respondent each from Venezuela, Argentina and Peru, while majority of the Baltic sample came from Latvia (24) with three respondents from Lithuania and three from Estonia.

Overall, the four most represented industries in the total sample (above 10\% of respondents) were: 1) finance, insurance and real estate, 2) other services, 3) industries not included in the list, and 4) high technology (see Figure 1). Across the three regions, however, the representation varied. In the USA sample, other industries and manufacturing dominated, in South America, those were other industries and agriculture, and in the Baltics, more respondents came from high technology and other services.

More USA respondents came from larger organizations while Baltic organizations were smaller in size. In South America, more respondents came from medium-sized organizations (100 - 500 people) (see Figure 2). This sample composition fairly reflects the business landscape of the three regions where organizations of the respective size dominate. Further, the sample was somewhat biased with respect to gender: men were slightly higher represented than women in South American and Baltic samples, but in the USA sample, men were slightly under-represented. Consistent with the job level (78\% of respondents held senior management or executive positions), respondents in all sub-samples were highly experienced (63\% had worked for more than 15 years since graduation) (see Table 2).

Table 2. Respondent characteristics.

\begin{tabular}{|c|c|c|c|c|c|c|c|c|}
\hline \multirow{2}{*}{ Respondent characteristics } & \multicolumn{2}{|c|}{ The USA } & \multicolumn{2}{|c|}{ South Am } & \multicolumn{2}{|c|}{ Baltics } & \multicolumn{2}{|c|}{ Total } \\
\hline & $\mathrm{N}$ & $\%$ & $\mathrm{~N}$ & $\%$ & $\mathrm{~N}$ & $\%$ & $\mathrm{~N}$ & $\%$ \\
\hline \multicolumn{9}{|c|}{ Gender } \\
\hline Female & 17 & 56.7 & 13 & 43.3 & 10 & 33.3 & 40 & 44.4 \\
\hline Male & 13 & 43.3 & 17 & 56.7 & 20 & 66.7 & 50 & 55.6 \\
\hline \multicolumn{9}{|c|}{ Job level } \\
\hline Senior management/ executive & 21 & 70.0 & 24 & 80.0 & 25 & 83.3 & 70 & 77.8 \\
\hline Middle management/ project management & 8 & 26.7 & 6 & 20.0 & 4 & 13.3 & 18 & 20.0 \\
\hline Professional or technical position & 1 & 3.3 & 0 & 0 & 1 & 3.3 & 2 & 2.2 \\
\hline \multicolumn{9}{|c|}{ Work experience since graduation } \\
\hline 5 years or less & 1 & 3.3 & 3 & 10.0 & 1 & 3.3 & 5 & 5.6 \\
\hline $6-10$ years & 2 & 6.7 & 5 & 16.7 & 4 & 13.3 & 11 & 12.2 \\
\hline $11-15$ years & 2 & 6.7 & 5 & 16.7 & 7 & 23.3 & 14 & 15.6 \\
\hline $16-20$ years & 3 & 10.0 & 3 & 10.0 & 9 & 30.0 & 15 & 16.7 \\
\hline 21 or more years & 21 & 70.0 & 13 & 43.3 & 8 & 26.7 & 42 & 46.7 \\
\hline No response & 1 & 3.3 & 1 & 3.3 & 1 & 3.3 & 3 & 3.3 \\
\hline
\end{tabular}




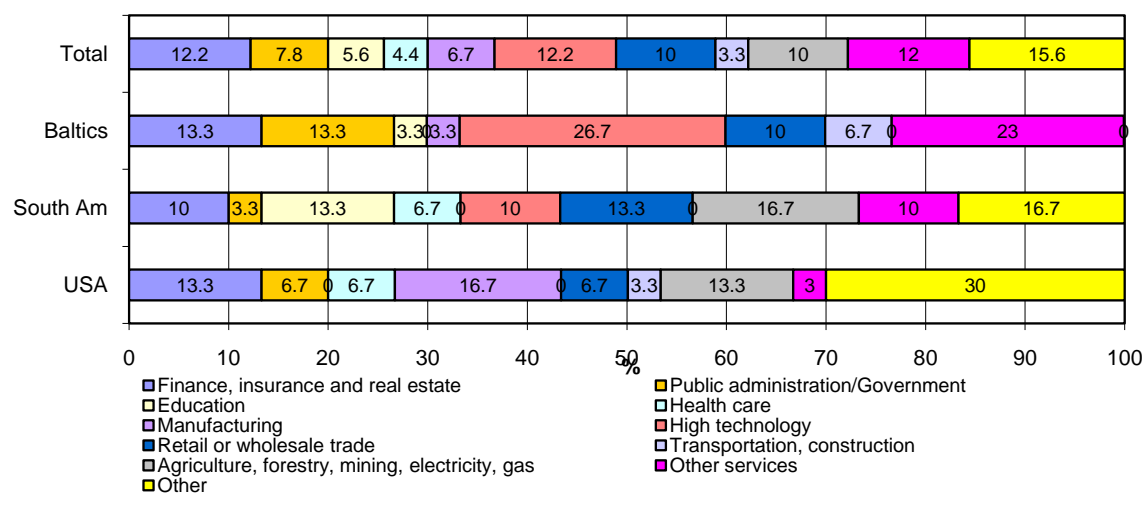

Figure 1. Industries represented in the sample.

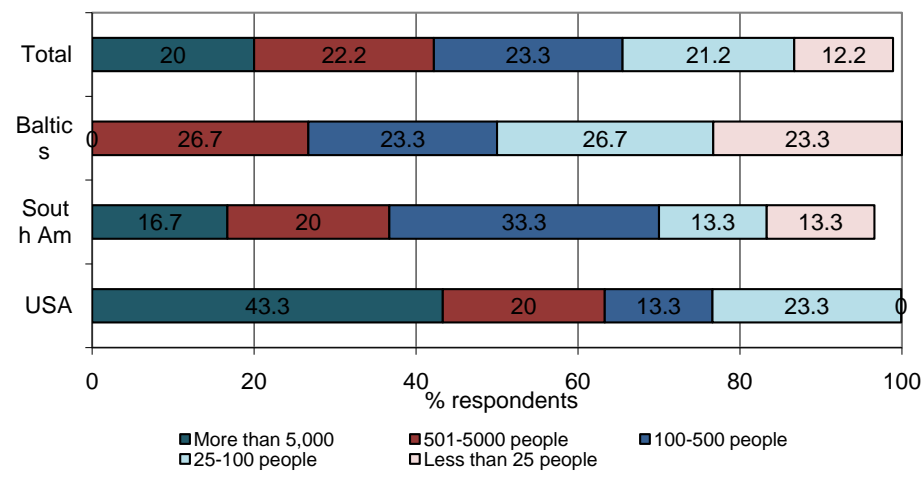

Figure 2. Organization sizes represented in the sample. ${ }^{*}$ Some sub-samples do not add up to $100 \%$ due to item non-response.

To determine the amount of change in their organizations, respondents were asked if their organizations had introduced any of the four types of change in the past five years: 1) introduced/abandoned major service/product lines, 2) underwent major restructuring, 3) significantly changed staff numbers and 4) underwent a major transformation in work processes. Overall, all four types of change were introduced to a high and approximately equal degree (as reported by $73 \%$ $80 \%$ of respondents). However, across regions, respondents perceived that some changes have been introduced more frequently than others. In South America, major change in product or service lines dominated (90\%), with the USA also dominating in major change in product or service lines (87\%). In the Baltics organizations, change in staffing had been slightly more widespread (93\%) while in the USA, this change was reported least frequently $(57 \%)$ in favour of other types of change.

\section{Data Collection}

Potential study participants were identified through personal and social media contacts as well as the "snowballing" method and invited to either telephone or face-to-face interviews through an invitation letter. The interviewees were provided with a copy of the general interview questions in advance except for the list of change skills found in the literature (Somerville \& Whelan-Berry, 2009) that required unprepared answers. Prior to the interview, they were also sent a 
consent form, approved by the Ethics Board of Hamline University, and participants were asked to sign it. Researchers in all regions used a standardized interview guide to ensure consistency of questions and response recording. Some interviews outside the USA were conducted in English, and when needed in Spanish and Latvian.

\section{Data Analysis}

In this study, we collected both quantitative and qualitative data. The numerical data were entered into SPSS for further analysis. This study involved descriptive statistics such as frequency counts, percentages and means with standard deviations. Statistical significance of between-group differences in means was obtained with the help of one-way ANOVA. If an overall difference across all three regions was discovered for an item, a post-hoc analysis was run to identify specific pair-wise differences. Differences across regions in percentages were established using a chi square test. Given the small sample size, no factors were controlled for, e.g., industry or organization size.

\section{Results}

Research Question \#1: Is the availability of change skills within organizations perceived differently across the three regions?

First, when asked without any prompting about change skills perceived to be present in their organization, $21 \%$ of the respondents could not name any organizational change skills. For those that could name some change skills, on average, they named 2.4 skills each, and the vast majority of the identified skills fell into the pre-established 11 categories (see Figure 3). The most frequent skill mentioned was communication (39\%), followed by managing the change process, interpersonal and social skills, establishing a vision and change leadership-skills that were mentioned by at least $10 \%$ of respondents. Chi square tests established three cases of regional differences in the skills that were identified. More USA respondents named communication (57\% vs. 23\% South Americans and $37 \%$ Baltic respondents) and managing the change process ( $40 \%$ vs. $10 \%$ Baltic respondents and no South Americans) than their other counterparts, and more Baltic respondents named understanding internal and external environment (17\% vs. $3 \%$ USA respondents and no South Americans).

In addition to the 11 groups of previously identified change skills, there were a few additional change skills identified by the respondents. The most popular change skill not on the original list was flexibility, which was mentioned by nine respondents (six from the Baltics and three from South America). Innovation skills were also highlighted by four respondents (two from South America, one from the Baltics, and one from the USA).

Next, the interviewees were provided with the 11 groups of change skills. They were asked what change skills they perceived were found inside their own organizations. For the convenience of comparisons, responses were assigned a numerical value (no $=0$, somewhat $=1$, yes $=2$ ) and means were calculated. The 
higher the mean, the more confident respondents were that a particular skill was present in their organization. Figure 4 shows the ranking of the 11 pre-determined skill groups according to their presence within organizations by the total sample values and also includes regional differences.

Overall, the majority of respondents were confident that all the presented change skills to some degree could be found in their organizations as means exceeded the value of " 1 ". The most frequently found skill was establishing the vision for change (mean $=1.57, \mathrm{SD}=0.64$ ), and the skill found least frequently was dealing with resistance and conflict (mean $=1.11, \mathrm{SD}=0.76$ ). Only one regional difference was statistically significant: understanding internal and external environment $(\mathrm{F}=3.236, p=0.044, \mathrm{df}=2)$. A post-hoc Tukey test established a pair-wise difference between the USA (mean $=1.2, \mathrm{SD}=0.76$ ) and South America $($ mean $=1.63, \mathrm{SD}=0.56)(p=0.041)$.

Research Question \#2: Is the importance of specific organizational change skills to successfully implement organizational change perceived differently across the three regions?

To address this research question, respondents were asked to rate the importance of the pre-determined change skills. Figure 5 ranks the 11 groups of skills by the total sample values in the diminishing order of importance, also showing the regional differences. Overall, all 11 groups were rated as quite important. On a 7-point scale, where a higher mean value means higher degree of importance, all ratings exceeded the scale midpoint of "4", managing the change process being the most important skill overall (mean $=6.4, \mathrm{SD}=1.07$ ), followed by change leadership, communication, trust and vision-skills with mean values above "6". On the other hand, forming coalitions and networks was rated the lowest (mean $=4.78, \mathrm{SD}=1.72$ ).

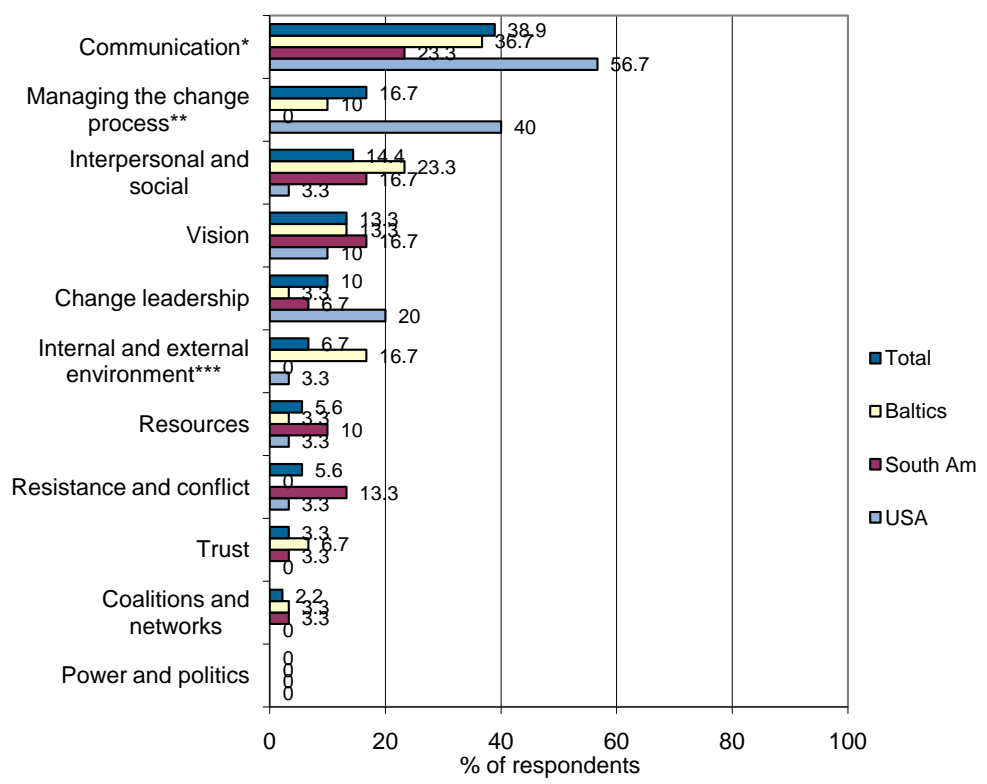

Figure 3. Change Skills Mentioned without Prompting. ${ }^{*}$ chi sq $=7.106, \mathrm{df}=2, p$ $=0.029 ;{ }^{\star *}$ chi sq $=18.720, \mathrm{df}=2, p<0.001 ;{ }^{* *}$ chi sq $=7.500, \mathrm{df}=2, p=0.024$. 


\begin{tabular}{|c|c|c|c|c|c|c|c|c|c|c|c|c|}
\hline \multirow[t]{2}{*}{ Change skills } & \multicolumn{3}{|c|}{ Total } & \multicolumn{3}{|c|}{ USA } & \multicolumn{3}{|c|}{ South Am } & \multicolumn{3}{|c|}{ Baltics } \\
\hline & Mean & SD & & Mean & SD & & Mean & SD & & Mean & SD & \\
\hline Vision & 1.57 & 0.64 & 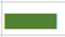 & 1.57 & 0.63 & 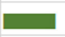 & 1.60 & 0.68 & & 1.53 & 0.63 & \\
\hline Resources & 1.46 & 0.69 & ש & 1.33 & 0.76 & 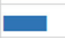 & 1.70 & 0.60 & 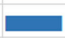 & 1.53 & 0.66 & 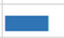 \\
\hline Trust & 1.45 & 0.66 & $\square$ & 1.33 & 0.76 & $\square$ & 1.55 & 0.57 & $\square$ & 1.47 & 0.63 & $\bar{\square}$ \\
\hline Int and ext environment* & 1.43 & 0.72 & 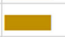 & 1.20 & 0.76 & $\square$ & 1.63 & 0.56 & 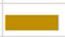 & 1.47 & 0.78 & 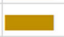 \\
\hline Managing the change process & 1.42 & 0.67 & 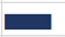 & 1.27 & 0.79 & $\square$ & 1.40 & 0.56 & 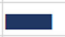 & 1.60 & 0.62 & \\
\hline Change leadership & 1.42 & 0.72 & 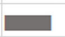 & 1.40 & 0.77 & 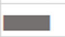 & 1.40 & 0.72 & 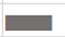 & 1.47 & 0.68 & \\
\hline Communication & 1.41 & 0.70 & 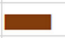 & 1.47 & 0.68 & 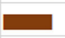 & 1.33 & 0.80 & 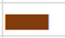 & 1.43 & 0.63 & 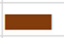 \\
\hline Interpersonal and social & 1.38 & 0.68 & $\bar{\square}$ & 1.30 & 0.70 & $\bar{\square}$ & 1.37 & 0.67 & $\bar{\square}$ & 1.47 & 0.68 & \\
\hline Coalitions and networks & 1.33 & 0.75 & $\square$ & 1.27 & 0.79 & 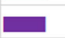 & 1.37 & 0.72 & & 1.37 & 0.77 & \\
\hline Power and politics & 1.33 & 0.72 & 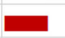 & 1.13 & 0.73 & ש & 1.47 & 0.68 & & 1.40 & 0.72 & \\
\hline Resistance and conflict & 1.11 & 0.76 & $\square$ & 0.93 & 0.79 & 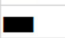 & 1.17 & 0.70 & 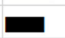 & 1.23 & 0.77 & \\
\hline * statistically significant diff & terence & at $\alpha=$ & 0.05 & & & & & & & & & \\
\hline
\end{tabular}

Figure 4. Presence of change skills within organizations.

\begin{tabular}{|c|c|c|c|c|c|c|c|c|c|c|c|c|}
\hline \multirow[b]{2}{*}{ Change skills } & \multicolumn{3}{|c|}{ Total } & \multicolumn{3}{|c|}{ USA } & \multicolumn{3}{|c|}{ South Am } & \multicolumn{3}{|c|}{ Baltics } \\
\hline & Mean & SD & & Mean & SD & & Mean & SD & & Mean & SD & \\
\hline Managing the change process & 6.40 & 1.07 & & 6.33 & 0.88 & & 6.59 & 0.78 & & 6.27 & 1.44 & \\
\hline Change leadership & 6.26 & 1.05 & & 6.07 & 0.98 & & 6.38 & 0.86 & & 6.33 & 1.24 & \\
\hline Communication & 6.21 & 1.16 & & 6.37 & 0.72 & & 6.38 & 1.02 & & 5.90 & 1.56 & \\
\hline Trust & 6.20 & 1.15 & 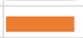 & 6.07 & 1.14 & & 6.38 & 0.90 & & 6.17 & 1.37 & \\
\hline Vision & 6.19 & 1.39 & & 6.27 & 0.91 & & 6.07 & 1.58 & & 6.23 & 1.61 & \\
\hline Interpersonal and social* & 5.79 & 1.36 & & 5.23 & 1.70 & & 6.04 & 1.18 & & 6.10 & 0.96 & \\
\hline Resources & 5.55 & 1.41 & & 5.63 & 1.33 & & 5.38 & 1.12 & & 5.63 & 1.75 & \\
\hline Resistance and conflict & 5.53 & 1.22 & & 5.53 & 1.25 & & 5.43 & 1.14 & & 5.63 & 1.30 & \\
\hline Int and ext environment & 5.52 & 1.32 & & 5.17 & 1.32 & & 7.79 & 1.15 & & 5.60 & 1.43 & \\
\hline Power and politics & 5.28 & 1.57 & & 5.43 & 1.33 & & 5.52 & 1.53 & & 4.90 & 1.81 & \\
\hline Coalitions and networks & 4.78 & 1.72 & & 4.60 & 1.40 & & 5.17 & 1.71 & & 4.57 & 1.98 & \\
\hline * statistically significant $\mathrm{c}$ & erence & 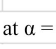 & & & & & & & & & & \\
\hline
\end{tabular}

Figure 5. Perceived importance of change skills.

The only statistically significant regional difference in the perceived importance of change skills was observed for interpersonal and social skills $(\mathrm{F}=4.014$, $p=0.022, \mathrm{df}=2)$. Further post-hoc Tukey test identified significant differences within specific paired values: South American (mean $=6.04, \mathrm{SD}=1.18, p=$ 0.056 ) and Baltic (mean $=6.10, \mathrm{SD}=0.96, p=0.033$ ) respondents considered this skill as more important than their counterparts in the USA (mean $=5.23$, $\mathrm{SD}=1.7$ ). Although not statistically significant, slight regional differences could also be observed for some other skills. The Baltic respondents rated communication and power and politics lower than the USA and South American samples, and South Americans considered forming coalitions and networks as somewhat more important than others.

\section{Discussion}

The overall purpose of this study was to explore whether perceptions of organizational change skills differ across nations, and we focused on three regions: the USA, South America and the Baltics. First, we examined if the availability of change skills within organizations was perceived differently across the three regions. Even though the respondents reported that their organizations had faced a high degree of change in the previous five years, $21 \%$ of respondents were unable to identify any organizational change skills without prompting. Further, on av- 
erage the respondents were only able to identify about two change skills each. Interestingly, the vast majority of skills that respondents could name off the top of their minds fell into the 11 established categories. This confirms the salience of the change skills as summarized by Somerville and Whelan-Berry (2009). Five skills stood out that respondents mentioned more frequently: communication, managing the change process, interpersonal and social skills, establishing vision for change and change leadership. There were some interesting cross-national differences. In the USA, where organizations have been dealing with changes very intensely for the past 30 years, communication and managing the change process were skills apparently honed within most organizations consistently. On the other hand, in the Baltics where dramatic changes were forced upon all the organizations over the past 25 years due to the overhaul of the socio-economic system organizations had to be vigilant and responsive to the environmental changes. Possibly that is why understanding internal and external environments was a skill that Baltic respondents could identify more frequently than others. These few differences led us to think that environmental conditions in different geographies may affect what change skills organizations develop.

Although respondents across all three regions could identify a limited number of change skills, when provided with the list of 11 change skills, the majority were confident that all of the change skills presented could be found in their organization. Establishing a vision for change was identified most often, but dealing with resistance and conflict least of all. Since resistance to change is still a wide-spread phenomenon in organizations (e.g., Craine, 2007; Burke, 2018), lack of skills to deal with it may hinder change success. There was quite high unanimity across samples in recognizing change skills when prompted, with one significant difference. Similarly to the Baltic respondents before, also South Americans were more likely to perceive that the skill of understanding internal and external environment was available in their organizations, possibly due to the fact that the country had started opening up to globalization 30 years ago.

\section{Conclusion}

These findings suggest that overall, the respondents from these three regions, who had been working in high change environments, had not been thinking of the importance of organizational change skills in relation to their change initiatives underway in their organizations even though these skills were available to them. Another possibility is that the respondents were not focused on a sufficient number of different skills that may be necessary for successful organizational change.

While there is a proliferation of organizational change research, Stouten, Rousseau and de Cremer (2018) found that practicing change managers are making relatively little use of this research. We suggest that if those leading and managing change initiatives recognize that there are at least 11 groups of change skills and cultivate those skills within the organization, this could increase the 
success rate of these initiatives.

Lastly, all 11 groups of change skills were rated as quite important by the respondents in all samples. Many respondents were obviously concerned about the operational aspect of change as managing the change process was rated as the most important skill. Also change leadership, communication, building trust and establishing a vision were considered very important. Organizations undergoing change would benefit from paying special attention to developing and using these skills. Interestingly, the skill of forming coalitions and networks was ranked lower, with more collectivist South Americans (Hofstede, 1984) attributing slightly higher importance to it than others. With more complex global operating environments (Burk, 2019), building social capital for organizational change through disciplined professional collaboration can be extremely helpful (Jones \& Harris, 2014). Individualistic cultures may find this skill more challenging. Similarly, the Baltic and South American respondents viewed interpersonal and social skills as more important than the USA respondents. Cultural characteristics may hardly explain this difference as the Baltics are more individualistic than South America. It is possible, however, that the size of organizations determined this perception when interactions in smaller and medium-sized organizations with fewer hierarchical layers than in large organizations, dominating the samples of the Baltics and South America, benefit from better interpersonal and social skills.

Overall, relatively few statistically significant regional differences emerged concerning what change skills are perceived to be available within their organizations and what specific organizational change skills are considered to be most important to successfully implement organizational change. While intuitively we agree with Jacobs et al. (2013) that "scholars of organizational change cannot continue to assume with a quiet heart, that the change patterns in their corner of the world reflect those experienced on a wider, global stage," this study suggests surprising similarities in relation to our two research questions in the USA, South America and the Baltics.

Findings of this research contribute to both the intersection of change management and cross-cultural management streams of literature as well as organizational change agent practices. The literature is enriched by the change skills framework and its perception among organizational leaders in three different geographies. The consistency in the perceptions across these three regions can form the basis for further exploration of this framework in other cultural settings to see if the current findings hold. On the other hand, for practitioners in global corporations, this suggests that cross-border dissemination of organizational change skills is possible providing attention is also paid to the unique national circumstances and organizational characteristics. For example, in countries that have recently experienced major socio-economic and political changes (such as the Baltics), organizational leaders need to be well versed in reading the internal and external environmental clues, while in smaller organizations interpersonal 
and social skills may play a more important role than in larger organizations.

Notwithstanding the important contributions of this exploratory empirical study, there are also some limitations. One limitation is the sample size of 30 for each of the three regions, which means that we were unable to consider differences in relation to organization size and industry type. Increasing the sample size in future research may result in finding further statistically significant variances. Second, convenience sampling limited our ability to control the study for pre-defined organizational change outcomes. In future, using stratified sampling method based on identified change success variables, researchers may model the relationship between certain change skills and the degree of change success. Another limitation is unbalanced representation of the regions. The bulk of the South American sample came from Colombia, and the majority of the Baltic respondents were from Latvia.

Undoubtedly key areas for future research are increasing the sample size, and researching change skills in relation to organization size and industry. In addition, including certain organizational outcomes in the research design, it could be established which change skills have made a more significant difference. For example, recent research (Waggoner, 2020), has suggested that political skills may be regarded as advanced behavioural competencies that could be used to advance the efforts of change agents. Moreover, change skills could be associated with the phase of organizational change in the participating organizations to see if there are times when certain skills are more needed than others. Future research should also include additional regions in different parts of the world to see if the findings are similar concerning the universality of change skills.

\section{Conflicts of Interest}

The authors declare no conflicts of interest regarding the publication of this paper.

\section{References}

Alas, R., \& Sharifi, S. (2002). Organizational Learning and Resistance to Change in Estonian Companies. Human Resource Development International, 5, 313-331. https://doi.org/10.1080/13678860210143550

Alas, R., Kaarelson, T., \& Rees, C. (2014). The Impact of Social, Political and Economic Changes on People Management in Estonian Organisations. Journal of Management and Change, 32/33, 77-88.

Al-Haddad, S., \& Kotnour, T. (2015). Integrating the Organizational Change Literature: A Model for Successful Change. Journal of Organizational Change Management, 28, 234-262. https://doi.org/10.1108/JOCM-11-2013-0215

Anand, N., \& Barsoux, J.-L. (2017). What Everyone Gets Wrong about Change Management. Harvard Business Review, November-December, 79-85.

Assis-Dorr, H., Palacios-Marques, D., \& Merigó, J. M. (2012). Social Networking as an Enabler of Change in Entrepreneurial Brazilian Firms. Journal of Organizational Change Management, 25, 699-708. https://doi.org/10.1108/09534811211254581 
Baumane, I. (2010). Change Management Experience in the Baltic States 1998-2009. Riga: Amrop.

Beer, M., \& Nohria, N. (2000). Breaking the Code of Change. Boston, MA: Harvard Business School Press.

Brakman, S., Garretsen, H., Van Marrekijk, C., \& Van Witteloostuijn, A. (2013). Cross-Border Merger and Acquisition Activity and Revealed Comparative Advantage in Manufacturing Industries. Journal of Economics \& Management Strategy, 22, 28-57.

https://doi.org/10.1111/jems.12007

Buono, A. F., Adams, S. M., \& Schwarz, G. M. (2019). Chapter 1: Preparing for High Impact Change: The Critical Role of Experiential Learning and Practice. In Preparing for High Impact Change, Experiential Learning and Practice (pp. 1-12). Northampton, MA: Edward Elgar Publishing Limited. https://doi.org/10.4337/9781788116954.00007

Buono, A., \& Subbiah, K. (2014). Internal Consultants as Change Agents: Roles, Responsibilities and Organizational Change Capacity. Organization Development Journal, 32, 35-53.

Burk, J. (2019). The Only Constant Is Change: Developing a Compelling Story to Enable Organizational Transformation. The International Journal of Knowledge, Culture, and Change Management: Annual Review, 19, 1-6. https://doi.org/10.18848/1447-9524/CGP/v19i01/1-6

Burke, W. (2011). A Perspective on the Field of Organization Development and Change: The Zeigarnik Effect. The Journal of Applied Behavioral Science, 47, 143-167. https://doi.org/10.1177/0021886310388161

Burke, W. (2018). Organizational Change: Theory and Practice (5th ed.). Thousand Oaks, CA: Sage.

By, R., Hughes, M., \& Ford, J. (2016). Change Leadership: Oxymoron and Myths. Journal of Change Management, 16, 8-17. https://doi.org/10.1080/14697017.2016.1137425

Craine, K. (2007). Managing the Cycle of Change. The Information Management Journal, 41, 44-50.

Elenurm, T. (2007). International Competitiveness and Organizational Change Drivers Anticipated by Estonian Managers in the Context of European Integration. Baltic Journal of Management, 2, 305-318. https://doi.org/10.1108/17465260710817500

Grady, V., \& Grady III, J. (2013). The Relationship of Bowlby's Attachment Theory to the Persistent Failure of Organizational Change Initiatives. Journal of Change Management, 13, 206-222. https://doi.org/10.1080/14697017.2012.728534

Greenwood, J. A., \& Sandomire, M. M. (1950). Sample Size Required for Estimating the Standard Deviation as a Percent of Its True Value. Journal of the American Statistical Association, 45, 257-260. https://doi.org/10.1080/01621459.1950.10483356

Hofstede, G. (1984). Culture's Consequences: International Differences in Work-Related Values (2nd ed.). Beverly Hills, CA: Sage Publications.

Hogg, R. V., Tanis, E. A., \& Zimmerman, D. (2015). Probability and Statistical Inference (9th ed.). Upper Saddle River, NJ: Pearson Education, Inc.

House, R., Javidan, M., Hanges, P., \& Dorfman, P. (2002). Understanding Cultures and Implicit Leadership Theories across the Globe: An Introduction to Project GLOBE. Journal of World Business, 37, 3-10. https://doi.org/10.1016/S1090-9516(01)00069-4

Jacobs, G., van Witteloostuijn, A., \& Christe-Zeyse, J. (2013). A Theoretical Framework of Organizational Change. Journal of Organizational Change Management, 26, 772-792. https://doi.org/10.1108/JOCM-09-2012-0137 
Jansson, N. (2013). Organizational Change as Practice: A Critical Analysis. Journal of Organizational Change Management, 26, 1003-1019. https://doi.org/10.1108/JOCM-09-2012-0152

Jones, M., \& Harris, A. (2014). Principals Leading Successful Organizational Change. Building Social Capital through Disciplined Professional Collaboration. Journal of Organizational Change Management, 27, 473-485. https://doi.org/10.1108/JOCM-07-2013-0116

Kirsch, C., Chelliah, I., \& Parry, W. (2012). The Impact of Cross-Cultural Dynamics on Change Management. Cross Cultural Management, 19, 166-195. https://doi.org/10.1108/13527601211219865

Kotter, J. (2008). A Sense of Urgency. Boston, MA: Harvard Business Press.

Kotter, J. (2012). Accelerate. Harvard Business Review, 90, 43-58.

Kumar, S. (2021). Inferential Statistics-Sampling Distribution, Central Limit Theorem and Confidence Interval. Data Science Blogathon. https://www.analyticsvidhya.com/blog/2021/01/inferential-statistics-sampling-distribut ion-central-limit-theorem-and-confidence-interval

Levasseur, R. E. (2013). People Skills: Developing Soft Skills-A Change Management Perspective. Interfaces, 43, 566-571. https://doi.org/10.1287/inte.2013.0703

Martínez, A., Belso-Martínez, J., \& Más-Verdú, F. (2012). Industrial Clusters in Mexico and Spain: Comparing Inter-Organizational Structures within Context of Change. Journal of Organizational Change Management, 25, 657-681. https://doi.org/10.1108/09534811211254563

McCauley, C. (2006). Developmental Assignments: Creating Learning Experiences without Changing Jobs. Greensboro, NC: Center for Creative Leadership Press.

Melnikas, B., Baršaukas, P., \& Kvainauskaité, V. (2006). Transition Processes and Integral Cultural Space Development in Central and Eastern European: Main Problems and Priorities. Baltic Journal of Management, 1, 201-212. https://doi.org/10.1108/17465260610663890

Momcilovic, O., Nikolic, G., \& Arsovski, S. (2016). Impact of the Skills of Leaders on the Management of Organizational Change in Small and Medium Enterprises. Journal of Business Paradigms, 1, 11-37.

Nadler, D., \& Tushman, M. (1990). Beyond the Charismatic Leader: Leadership and Organizational Change. California Management Review, 32, 77-97. https://doi.org/10.2307/41166606

Nikolaou, I., Gouras, A., Vakola, M., \& Bourantas, D. (2007). Selecting Change Agents: Exploring Traits and Skills in a Simulated Environment. Journal of Change Management, 7, 291-313. https://doi.org/10.1080/14697010701779173

O’Hagan-Luff, M., \& Berrill, J. (2016). US Firms-How Global Are They? A Longitudinal Study. International Review of Financial Analysis, 44, 205-216.

https://doi.org/10.1016/j.irfa.2016.01.021

OECD (2003). OECD Economic Surveys: The Baltic States. Paris: Organisation for Economic Co-operation and Development.

Onderick-Harvey, E. (2018). 5 Behaviors of Leaders Who Embrace Change. Harvard Business Review. https://hbr.org/2018/05/5-behaviors-of-leaders-who-embrace-change

Pérez, R. (2009). Modelo de Modernización para la Gestión de las Organizaciones. Editorial, Bogotá: Universidad EAN.

Powell, W. (2001). The Capitalist Firm in the Twenty-First Century: Emerging Patterns in 
Western Enterprise. In P. DiMaggio (Ed.), The Twenty-First Century Firm: Changing Economic Organization in International Perspective. Princeton, NJ: Princeton University Press.

Schaffer, R. (2010). Mistakes Leaders Keep Making: How to Overcome Deep-Seated Obstacles to Change. Harvard Business Review, September, 86-91.

Somerville, K. A., \& Whelan-Berry, K. S. (2009). Organizational Change Skills: A Study of the Literature and Education Available from American and Canadian MBA Programs. The International Journal of Knowledge, Culture \& Change Management, 9, 55-65. https://doi.org/10.18848/1447-9524/CGP/v09i10/49822

Somerville, K., \& Turner, D. M. (2013). Managers' Perceptions of Organizational Change Skills-Within Their Own Organization and Those Sought from Management Consultants. In A. Buono, L. Caluwe, \& A. Stoppelenberg (Eds.), Research in Management Consulting: Volume on Exploring the Professional Identity of Management Consultants. Charlotte, NC: Information Age Publishing.

Soriano, D. R. (2012). Change Management in the Entrepreneurial Latin-American Organizations: An Overview. Journal of Organizational Change Management, 25, 653-656. https://doi.org/10.1108/09534811211254554

Spencer, L., \& Spencer, S. (1993). Competence at Work: Model for Superior Performance. New York: John Wiley \& Sons.

Stiglitz, J. (2002). El malestar en la globalización. Bogotá: Taurus.

Stouten, J., Rousseau, D. M., \& De Cremer, D. (2018). Successful Organizational Change: Integrating the Management Practice and Scholarly Literatures. Academy of Management Annals, 12, 752-788. https://doi.org/10.5465/annals.2016.0095

Triandis, H. (1993). The Contingency Model in Cross-Cultural Perspective. In M. M. Chemers, \& R. Ayman (Eds.), Leadership Theory and Research: Perspectives and Directions (pp. 167-188). San Diego, CA: Academic Press.

Tsui, A., Nifadkar, S., \& Ou, A. (2007). Cross-National, Cross-Cultural Organizational Behavior Research: Advances, Gaps, and Recommendations. Journal of Management, 33, 426-478. https://doi.org/10.1177/0149206307300818

Van der Smissen, S., Schalk, R., \& Freese, C. (2013). Organizational Change and the Psychological Contract. Journal of Organizational Change Management, 26, 1071-1090. https://doi.org/10.1108/JOCM-08-2012-0118

Waggoner, D. P. (2020). The Use of Political Skill in Organizational Change. Journal of Organizational Change, 33, 753-763. https://doi.org/10.1108/JOCM-12-2018-0357

Warrick, D. (2006). Teaching and Championing OD: Designing an Introductory Course for Students and Managers. Organization Development Journal, 24, 92-97. 